\title{
Poem
}

\section{Salt peanuts}

My dad in the neonatal ICU as a med student was kind of responsible, at least for five minutes for keeping all of those babies alive, but he tried not to think about it. He adjusted miniature IVs.

He recorded vital signs on charts and signed as illegibly as possible, to seem official. The babies didn't know how frail they were. They thought they were normal puppies.

They thought he was their dog mother.

But the machines were how they ate and breathed.

The machines in charge of keeping track of heart function sounded like dripping tap water or, at times, the silver resonance of a tuning fork. The sounds crossed.

There was almost a steady rhythm.

There was almost a tune "Salt Peanuts" by Dizzy Gillespie, my dad thought but none of the nurses had heard of it.

They heard heart monitors. They had clean sheets to fold. So he had to wait thirty years to tell me and my brother in the car on the way to dinner, as if he heard our healthy hearts and lungs pumping, and thought of it as if we were old enough now. 